[Thank you for showing interest in this paper! The final published version is at http://dx.doi.org/10.1080/00455091.2017.1320201. Please cite that version.]

\title{
Beliefs Do Not Come in Degrees
}

\author{
Andrew Moon
}

andrewmoon616@gmail.com

\begin{abstract}
Philosophers commonly say that beliefs come in degrees (or that beliefs are graded or that there are partial beliefs). Drawing from the literature, I make precise three arguments for this claim: an argument from degrees of confidence, an argument from degrees of firmness, and an argument from natural language. I show that they all fail. I also advance three arguments that beliefs do not come in degrees: an argument from natural language, an argument from intuition, and an argument from the metaphysics of degrees. On the basis of these arguments, I conclude that beliefs do not come in degrees. [Word Count: 99]
\end{abstract}

Keywords: belief; confidence; degrees of belief; partial belief; degrees

\section{Introduction}

This paper is a work in metaphysics and philosophy of mind. I am concerned with whether a mental state or property - belief - comes in degrees. Some things come in degrees. Mass, height, heat, and distance come in degrees. Dogs, water, citizenship, and pregnancy do not. The thesis of this paper is that beliefs belong in the second group, not the first group.

I have said that this paper is a work in metaphysics. Now, the view that belief comes in degrees at least appears to play a prominent role in normative disciplines such as formal epistemology and decision theory. Does my paper undermine the worthy endeavors of these disciplines? Not necessarily. At least some formal epistemologists are technically defining 'belief' and then saying that the thing picked out by 'belief', according to their stipulated definition, is something that comes in degrees. For example, Richard Jeffrey $(1970,161)$ writes of his willingness to 'use “degree-of-belief"... as a 
technical term,' and follows Frank Ramsey (1931) by defining 'degree-of-belief' in terms of decision theoretic concepts. ${ }^{1}$ Jeffrey famously writes, 'Our ordinary notion of belief is only vestigially present in the notion of degree of belief. I am inclined to think Ramsey sucked the marrow out of the ordinary notion' $(1970,171-172)$.

In this paper, I'll set aside the question of whether Ramsey successfully sucked the marrow out of the ordinary notion. ${ }^{2}$ My point is that so long as formal epistemologists and decision theorists are, like Jeffrey, using 'belief' in a technically-defined sense, and not in its ordinary sense, they are making no commitments about the question of whether beliefs come in degrees. Hence, my discussion is at least not directly relevant to their work. Similarly, if someone technically defined the term 'God' to mean Ralph Nader and then proceeded to argue that Nader does not exist (only using 'God' whenever she meant Ralph Nader), philosophers of religion would not find such claims relevant to their work.

Some philosophers may simply be intending to communicate that confidence comes in degrees when they say, 'Beliefs come in degrees.' I wholeheartedly agree that confidence comes in degrees. However, I am arguing that beliefs do not come in degrees. I will say more about the relationship between belief and confidence in coming sections, but for now, I'll simply note that it is at least not obvious that 'Belief comes in degrees' is equivalent to 'Confidence comes in degrees.' Hence, it is at least not obvious that my thesis commits me to the radical conclusion that confidence does not come in degrees.

Some may now think that my thesis is so unradical that it is uninteresting. Here are four points to address this concern. First, there are a number of arguments, normally

\footnotetext{
${ }^{1}$ See Lina Erikkson and Alan Hajek (2007) for a helpful history and discussion.

${ }^{2}$ For arguments that the marrow has not been sucked out, see Buchak (2014), Ross and Schroeder (2014), and Weisberg (forthcoming).
} 
in the epistemological literature, both for and against the claim that beliefs come in degrees. The fact that there are these arguments, which I will assess in this paper, is evidence that people find the thesis interesting. Second, I suspect that some philosophers, including epistemologists, have not taken the time to think carefully through the distinctions between 'belief', 'confidence', 'credence', and related terms. This paper can help with conceptual ground clearing. Third, many philosophers, when talking about belief, feel the need to use expressions like 'outright belief', 'binary belief', 'full belief', 'all-out belief', or 'all-or-nothing belief', as if there were such a thing as degreed (or partial or graded) belief with which to contrast. ${ }^{3}$ If my thesis is successfully defended, then we can just cleanly and simply use 'belief', no qualifications necessary. Lastly, even if this paper does not have immediate implications for formal epistemology and decision theory, neither do most metaphysical questions, such as whether there are universals, or whether a person endures or perdures. The question of whether a facet of reality - belief - has the property of coming in degrees might be intrinsically interesting to philosophers.

In $§ 1$, I present and criticize the common confidence argument that beliefs come in degrees. In $§ 2$, I discuss two arguments from natural language: one in favor of my thesis and one against it. I conclude that both arguments have limited persuasive power since they depend on premises that are not likely to be shared by dissenters. In $§ 3, \mathrm{I}$ make precise a common argument that beliefs do come in degrees, what I call the

\footnotetext{
${ }^{3}$ For 'outright belief', see Wedgwood (2008, 4), Fantl and McGrath (2009, 128), and Clarke (2013, 1). For 'binary belief', see Christensen $(2004,12)$, Erikkson and Hajek $(2007,206)$, and Tang $(2016$, 63). For 'full belief', see Erikkson and Hajek $(2007,206)$, Buchak $(2014,285)$, Lennertz $(2015,1)$, and Weisberg (forthcoming). For 'all-out belief', see Holton (2008, 36-37). For 'all-or-nothing belief', see Christensen $(2004,12)$, Buchak $(2014,285)$, and Sturgeon $(2008,140)$. If people could see that belief does not come in degrees, then all these qualifications would be unnecessary.
} 
firmness argument, and I argue that it fails. I end the section by briefly arguing, on the basis of simple intuition, that beliefs do not come in degrees. Lastly, in $\S 4$, I explore the metaphysics of degrees and then defend a new and more substantive argument that beliefs do not come in degrees, what I call the determinables argument.

\section{The Confidence Argument}

In this section, I show that a prominent argument that beliefs come in degrees rests on an unsupported assumption. One reason many epistemologists cite for thinking that beliefs come in degrees is that attributing degrees of confidence is intuitive. In the introduction to a volume of collected papers called Degrees of Belief, Franz Huber (2009) opens with the following remarks:

Degrees of belief are familiar to all of us. Our confidence in the truth of some propositions is higher than our confidence in the truth of other propositions. We are pretty confident that our computers will boot when we push their power button, but we are much more confident that the sun will rise tomorrow... The higher an agent's degree of belief for a particular proposition, the higher her confidence in the truth of that proposition... The purpose of this book is to provide a comprehensive overview and assessment of the currently prevailing theories of degrees of belief (1).

Jeremy Fantl and Matthew McGrath (2009) write,

We are more confident of the truth of some propositions than others. You are presumably more confident that the next British prime minister will be a Conservative than a Liberal Democrat... We should allow, then, that there is such a thing as graded belief - roughly being more or less confident of the truth of a proposition. But there also seems to be such a thing as outright believing, which is binary (128).

Scott Sturgeon (2008) writes that

[B]elief can seem coarse-grained. It can look like a three-part affair: either given to a claim, given to its negation, or withheld... [B]elief can seem fine-grained. It can look as if one invests levels of confidence rather than all-or-nothing belief. In this sense of belief one does not simply believe, disbelieve or suspend judgement. 
One believes to a certain degree, invests confidence which can vary across quite a range (140).

David Christensen (2004) writes that

[B]elief is an attitude that one can either take, or fail to take, with respect to a given claim... Nevertheless, the binary model does not provide the only plausible way of conceiving of belief. It is clear, after all, that we have much more confidence in some things we believe than in others. Sometimes our level of confidence in the truth of a given claim decreases gradually — say, as slight bits of counterevidence trickle in... This suggests that underlying our binary way of talking about belief is an epistemic phenomenon that admits of degrees (13-14). ${ }^{4}$

Notice that although these philosophers think that beliefs come in degrees, other

remarks indicate that they also are sympathetic to the 'binary model' (Christensen) or a 'coarse-grained' view (Sturgeon) or the existence of 'outright' belief (Fantl and McGrath). There is no inconsistency here; they might hold that one type of belief comes in degrees and another type does not. But it at least seems that they are making the positive claim that at least one type of belief comes in degrees.

Here are three more points about the above quotes. First, the claims of Huber, et.al. are about belief and not about something merely belief-like that shares some of belief's properties. ${ }^{5}$ Second, they are trying to illustrate how beliefs come in degrees. Third, they seem to think that by illustrating the plausible thesis that confidence comes in degrees, it thereby follows that they have shown how belief (or a certain type of belief) comes in degrees.

This supposed illustration of belief coming in degrees is best explained by the hypothesis that they are assuming a premise like one of the following:

\footnotetext{
${ }^{4}$ For more examples, see Harman (1986, 22), Foley (1992, 111), Erikkson and Hajek (2007, 209), Frankish (2009, 75), Staffel (2013, 3537), and Konek (2016, 509-510).

${ }^{5}$ Hence, although some philosophers might say, 'I just meant confidence when I said "belief', ' I am now taking them at their word that they mean belief when they say 'belief'.
} 
Assumption 1: The property of having confidence that $p$ is identical to the property of having belief that $p$.

Assumption 2: 'Belief' and 'confidence' pick out the same thing.

They then infer that since the property of having confidence, or the thing picked out by 'confidence', comes in degrees, it follows that belief comes in degrees.

However, no reasons are given for Assumptions 1 and 2. They seem to just be assumed. Now, on the face of things, belief and confidence $d o$ seem to be similar sorts of mental entities; perhaps they are identical. On the other hand, our having formed different words for them is some evidence that they are distinct. So, as it stands, I see no convincing argument here that beliefs come in degrees. We will have to look elsewhere for better arguments. ${ }^{6}$

\section{Arguments from Natural Language}

In $\S 2.1$ and $\S 2.2$, I provide two arguments that appeal to natural language: one that is in favor of my thesis and one that is against it. Although I find the argument in favor of my thesis to be convincing, I admit that both arguments will have limited persuasive power for those who disagree.

\subsection{An Argument from Language that Beliefs Do Not Come in Degrees}

In this section, I start by presenting a weak, but instructive, version of an argument that beliefs do not come in degrees. I then end the section by presenting a stronger version of that argument.

\footnotetext{
${ }^{6}$ Thanks to Kenny Boyce, David Christensen, and John Turri for help on the points in this section.
} 
Jay has the belief that unicorns are real. He also has confidence that this is so.

We see in the previous two sentences that both belief and confidence can be ascribed by a noun. Now consider,

1) 'I have much confidence that she is the one.'

2) 'I have little confidence that she is the one.'

These ordinary English sentences make perfect sense. Reflection on (1) and (2) makes it seem plausible that confidence comes in degrees. Since belief, like confidence, can also be ascribed by a noun, it might be thought that this method will show that beliefs comes in degrees. But consider that

3) 'I have much belief that she is the one.'

4) 'I have little belief that she is the one.'

are nonsensical. This method does not show that beliefs come in degrees.

On the contrary, the fact that (3) and (4) are nonsensical makes it seem plausible that beliefs do not come in degrees. Consider the following simple argument: if beliefs come in degrees, then (3) and (4) make sense; (3) and (4) do not make sense; therefore, beliefs do not come in degrees. This argument is weak, however, since the first premise can easily be disputed. Why think that if beliefs come in degrees, (3) and (4) must make sense? This is not obvious.

A stronger version of this argument can be given. Consider the distinction between mass nouns and count nouns. ${ }^{7}$ Dean Zimmerman (1995) usefully summarizes,

There are familiar syntactic criteria for the distinction: count nouns admit of pluralization, can occur with numerals, take 'a' and 'every' in the singular and 'few' and 'many' in the plural; while mass nouns take singular verbs, cannot occur with numerals, take determiners like 'much' and 'little' rather than 'few' and 'many' and so on (53).

\footnotetext{
${ }^{7}$ The following argument was greatly helped by correspondence and discussion with Mark Steen.
} 
Examples of count nouns are 'deer', 'tree, 'toy', and 'chimney'. Examples of mass nouns are 'stamina', 'energy', 'strength', and 'lava'. Note that paradigm propositional attitudes that come in degrees are all denoted by mass nouns: 'confidence', 'doubt', 'hope', 'fear', 'desire'. We can properly say, 'I have little doubt that they can do it,' 'I have much fear that they can do it,' and 'I have little hope that they can do it,' in addition to (1) and (2). On the other hand, things denoted by count nouns typically do not come in degrees.

However, it is incorrect to say that all nouns are either a mass noun or a count noun simpliciter. Rather, their occurrences are either one or the other. I can have little hope that she is the one, but I can also have $a$ hope that she is the one. In the previous sentence, 'hope' occurred as both a mass noun and also as a count noun. 'Belief' can also occur as either a mass noun or a count noun. Although it typically occurs as a count noun, in the following sentence,

5) 'There is more religious belief in this century than in the previous one,' 'belief' is used as a mass noun.

Here, now, is a stronger version of the argument from natural language that beliefs do not come in degrees:

i) If a propositional attitude $\mathrm{X}$ comes in degrees, then higher or lower degrees of $\mathrm{X}$ can be properly attributed to a person by an occurrence of a mass noun.

ii) Higher or lower degrees of belief cannot be properly ascribed to a person by an occurrence of a mass noun.

iii) Therefore, beliefs do not come in degrees.

Consider (i). One can talk of much hope, little confidence, much desire, and so on. For any paradigm propositional attitude that comes in degrees, higher or lower degrees of that 
attitude can be attributed to a person by way of an occurrence of a mass noun. This is inductive evidence for (i).

Consider (ii). One cannot ascribe higher or lower degrees of belief to a person with 'belief'. (5) does ascribe belief by way of a mass noun, but this only ascribes a number of single beliefs to a population, not a degree of belief to a single individual. Whenever belief is ascribed to a single person by way of a noun, it is by the occurrence of a count noun and not a mass noun. That is why (3) and (4) do not make sense. From (i) and (ii), it follows that beliefs do not come in degrees.

\subsection{An Argument from Language that Beliefs Come in Degrees}

I find the second argument in $\S 2.1$ to be convincing. However, others might not. Scott Sturgeon (2008) writes,

After all, predicates of the form 'believes that $\mathrm{P}$ ' look to be gradable. We can append modifiers to belief predicates without difficulty-John believes that $\mathrm{P}$ more than Jane does. And we can conjoin the negation of suchlike without conflict-John believes that P but not fully. These linguistic facts indicate that predicates of the form 'believes that P' are gradable (142).

If Sturgeon thinks it is natural to say,

6) 'John believes that P more than Jane does,'

and

7) 'John believes that P but not fully,'

then he will probably countenance sentences such as

8) 'John has more belief that P than Jane does.'

These sentences might be taken as evidence that beliefs come in degrees. They might also be taken to be evidence that premise (ii), of my above argument, is false. So, 
Sturgeon might say that what I earlier called nonsensical are actually fine and meaningful sentences of ordinary English.

It appears that we have an intuition clash regarding what makes sense in ordinary English. To emphasize this clash, note that just a few short years before Sturgeon's paper was published, P.M.S. Hacker (2004) appealed to similar sentences to argue that beliefs do not come in degrees! He writes,

But there are no degrees of belief... I cannot believe that $p$ more than you do, although I may be more certain than you that $p$. I cannot believe that $p$ just a little or very much, although I can be inclined a little or very much inclined to believe that $p(192)$.

How do we break this impasse? At this point, I will simply conclude that these arguments from natural language will likely not be persuasive to the opposing party who has different intuitions. We will have to move to other arguments. (In §3.1, I will explain why I think none of (6)-(8) gives us reason to think that beliefs come in degrees.)

\section{The Firmness Argument and the Intuition Argument}

In $\S 3.1$, I present and criticize the firmness argument that beliefs come in degrees. In $\S 3.2$, I present the intuition argument that they do not come in degrees.

\subsection{The Firmness Argument}

Daniel Hunter (1996) writes,

Belief is sometimes taken to be an all-or-nothing affair... At other times, however, we wish to think of belief as a matter of degree, not as an all-or-nothing matter. We recognize that there are some things we believe more strongly than others. For example, I believe that $2+2=4$ and I also believe that Neanderthals buried their dead, but I believe the former proposition much more firmly than the latter (75).

Richard Pettigrew (2015) writes, 
Our beliefs come in degrees; we believe some more strongly than others. For instance, I believe that the sun will rise tomorrow more strongly than I believe that it will rise every morning for the coming week; and I believe both of these propositions much more strongly than I believe that there will be an earthquake tomorrow in Bristol.

Consider some more examples:

9) 'Adam firmly believes that Santa exists.'

10) 'Adam very firmly believes that Santa exists.'

11) 'Adam believes that Santa exists more firmly than Esther does.'

12) 'Adam believes, with some doubt, that it will snow tomorrow.'

13) 'Adam believes with certainty that it will snow tomorrow.'

14) 'Adam believes that it will snow tomorrow but isn't certain about it. ${ }^{98}$

(Note that 'firmly' in (9)-(11) could have been replaced with 'strongly'. Since 'firmly' and 'strongly' have similar enough meanings for the purposes of this paper, I will stick to using 'firmly'.) Call these sentences 'modified-belief ascriptions'. Unlike the disputable sentences (6)-(8) from the previous section, modified-belief ascriptions are beyond reproach. Hunter and Pettigrew seem to think that the fact that they are sometimes true is good evidence that beliefs come in degrees. Call this the firmness argument.

The argument fails. Although a property of something might come in degrees, the thing itself might not. A deer has mass, and mass comes in degrees; a tree has height, and height comes in degrees. But neither the deer nor the tree come in degrees. I might see a panda with much clarity. Although the clarity with which I see the panda might come in degrees, my seeing the panda does not. Similarly, the firmness (or doubt or certainty) with which a belief is held might come in degrees, but it does not follow that

\footnotetext{
8 'Certainty' and 'certain' in (13) and (14) refer to psychological certainty, a state that entails the instantiation of no epistemic properties (e.g., justification). Sometimes, 'certainty' refers to epistemic certainty, a state that entails the instantiation of a great deal of justification.
} 
the belief itself does. ${ }^{9}$ So, (9)-(14) do not give us good reason to think that beliefs come in degrees but only that some properties of beliefs do.

But then what are (9)-(14) ascribing? What is it for a belief to be held with firmness? Plausibly,

15) $S$ 's belief that $p$ is held firmly if and only if $S$ believes that $p$ and $S$ would not easily give up the belief that $p$.

Furthermore, the degree of firmness with which $S$ 's belief that $p$ is held is proportional to how easy it would be for $S$ to give up the belief that $p$. This relationship can be expressed with the following biconditional:

16) $S$ believes that $p$ more firmly than $T$ believes that $p$ if and only if $S$ believes that $p$, $T$ believes that $p$, and $S$ would give up the belief that $p$ less easily than $T$ would. The property of firmness is roughly what some formal epistemologists have called entrenchment. ${ }^{10}$

The following biconditionals show how the presence or absence of certainty with which $S$ believes that $p$ is related to confidence:

17) $S$ believes with certainty that $p$ if and only if $S$ believes that $p$ and is completely confident that $p$.

\footnotetext{
${ }^{9}$ P.M.S. Hacker $(2004,192)$ concurs: 'Of course, one may strongly or firmly believe that $p$ (though not "weakly" or "moderately"), but this does not indicate a degree of belief. It signifies the strength or firmness with which one cleaves to the belief one has.'

${ }^{10}$ See Gardenfors and Makinson (1988), Rott (2009), Huber (2009, 22; 2016, sect. 3.4), and Smith (2016, 174). Rott writes, "A measure of the firmness of belief can be seen in their invulnerability, that is, the resistance they offer against being given up" (303). However, I disagree with Rott to the extent that he, like Hunter, seems to identify the degree of firmness of belief with the degree of belief itself. On the other hand, Huber (2016, sect. 3.4) writes, "It is, however, fair to say that belief revision theorists distinguish between degrees of belief and entrenchment. Entrenchment, so they say, characterizes the agent's unwillingness to give up a particular qualitative belief, which may be different from her degree of belief for the respective sentence or proposition." However, I disagree with Huber and those he mentions to the extent that they think that belief comes in degrees. I would have fewer qualms, however, if these philosophers proposed to use 'degree of belief' as a technical term for 'degree of firmness of belief'. Thanks to a referee of this journal for helpful discussion. Cf. Audi $(2011,100)$.
} 
18) $S$ believes that $p$ but is not certain that $p$ if and only if $S$ believes that $p$ but is not completely confident that $p$.

How do we express the doubt in (12)? The following biconditional seems correct:

19) $S$ believes, with some doubt, that $p$ if and only if $S$ believes that $p$ but has a degree of confidence less than complete confidence that $p .{ }^{11}$

To sum up, the modified-belief ascriptions (9)-(14) only ascribe some degree of firmness or some degree of confidence and a non-degreed belief to a subject. There is no good reason to think that they ascribe a degree of belief.

The discussion of this section also reveals a response to the argument from (6)(8) in §2.2. The intended meanings of (6) and (8) are more naturally expressed by the modified-belief ascription, 'John believes that P more firmly [or with more confidence] than Jane does', and the intended meaning of (7) by 'John believes that P but isn't certain about it.' When I hear (6)-(8) in such a way that they don't sound bad, it is because I am hearing them as these modified-belief ascriptions; when I try to read them literally, they still seem nonsensical. So, as with (9)-(14), we can see that there is no good reason to think that degrees of belief are being ascribed by (6)-(8).

Here is an analogy. Suppose a friend replies to something I say by remarking, 'That's very true!' One might think that my friend's reply attributes a high degree of truth to my statement, and therefore, that truth comes in degrees. But this would be a weak argument. More plausibly, my friend is merely expressing that my sentence is true and is very relevant to the situation. Hence, even if 'That's very true' is a fine English sentence, the fact that it can be easily paraphrased into a sentence that does not ascribe a degree of

\footnotetext{
${ }^{11}$ Of course, there is much to explore about the natures of confidence, doubt, and certainty that is beyond the scope of this paper. I explore them in Moon (draft). See also Moon (forthcoming) for an in-depth exploration of the nature of doubt.
} 
truth undercuts any implication that truth comes in degrees. This is also the case if I say, 'She is very pregnant,' about someone who is in a late term, or, 'After that experience, he is more alive now than ever,' about someone who has recovered from an illness. We should not conclude that either pregnancy or life comes in degrees; something else comes in degrees, like the baby's degree of development or the person's degree of energy. A similar situation applies to (6)-(8). These considerations undercut the argument of $\S 2.2$ that beliefs come in degrees. Since the argument of $\S 2.1$ is left standing, I conclude that natural language overall supports the view that beliefs do not come in degrees.

One last point. It is tempting to think that we can simplify things even further by saying that the degree of firmness with which a belief is held just is the degree of confidence with which it is held. But we should resist this temptation. Suppose Fred reads what he believes is an infallible religious text and comes to believe that it will rain on January 1, 3000 with a moderately high degree of confidence. He is not maximally confident because he recognizes that he is a fallible interpreter. Later, he has a vision of an angel (as would be expected in his religion) who tells him that any future evidence, either for or against his belief, will be misleading. With absolute trust in this vision, he continues to hold his belief that it will rain on January 1, 3000 with a moderately high degree of confidence. On future occasions, when people give him evidence for and against his belief, he holds firmly to it with exactly that degree of confidence.

Eventually, at an old age, he has even forgotten the vision but continues to believe with that same degree of confidence that it will rain on January 1, 3000, but now it is simply out of habit. Virtually nothing could sway his belief, even the appearance of another angel. In this case, the degree of firmness with which Fred's belief is held is extremely 
high; his confidence, however, is still only moderately high. Hence, we should not identify degree of firmness with degree of confidence. ${ }^{12}$

\subsection{The Intuition Argument}

Consider the following analogy. My seeing a panda does not seem to be the sort of thing that comes in degrees. I just see the panda, and there cannot be much or little of the seeing. Pointing out that I could see the panda clearly or very clearly should not diminish this intuition. Similarly, Jay's belief that unicorns are real does not seem to be the sort of thing that comes in degrees. He just believes this proposition, and there cannot be much or little of that belief. Pointing out that he can hold this belief firmly or very firmly or with confidence or with much confidence should not diminish this intuition. We should conclude, as with seeings, that beliefs are not the sort of things that come in degrees.

Notice that there is no appeal in this argument to what is natural to say in ordinary English, as in §2; I am appealing directly to our intuitions about what sort of thing belief is. And on that basis, we are justified in concluding that beliefs do not come in degrees.

\footnotetext{
${ }^{12}$ Thanks to Crystal Allen and Philip Swenson for help formulating the case. Notice also that the property of firmness can also be a property of one's suspension of judgment. An agnostic, for example, who suspends judgment about God's existence might be very firm in his withholding. Some people are psychologically such that it would be extremely hard for them to move to either atheism or theism. Similarly, one could have a high degree of confidence that $p$ but be such that she would easily give up that degree of confidence; and one could have a low degree of confidence that $p$ but be such that she would not easily give up that degree of confidence.
} 


\section{The Metaphysics of Degrees and the Determinables Argument}

In $\S 4.1-\S 4.2$, I explore more systematically the question of what it is for something to come in degrees. On the basis of this exploration, I present a novel argument in $\S 4.3$ that beliefs do not come in degrees.

\subsection{The Metaphysics of Degrees and the Determinables-Determinates Condition}

What sorts of things come in degrees? We can answer this question by first answering what sorts of things exist. Following Bigelow and Pargetter (1988), let us distinguish between individuals and substances. Individuals - concrete entities such as rocks, trees, and dogs - can be counted. We can sensibly ask how many dogs are in the room. Individuals are always designated by count nouns. And clearly, individuals are not the sorts of things that come in degrees; rocks, trees, and dogs do not come in degrees.

(Suppose someone thinks that beliefs are concrete entities-e.g., mental representations - existing in the brain. ${ }^{13}$ If beliefs are such concrete entities, then they are individuals. Individuals do not come in degrees. Therefore, beliefs do not come in degrees. Some will not accept this theory of the nature of belief and so will not be convinced by this argument. I mention it briefly for those who do accept it.)

Substances, such as water, gold, and lava, cannot be counted. We do not ask 'How many?' but 'How much?' For example, we can sensibly ask how much lava is in the room. Furthermore, substances are always designated by mass nouns. Now, it is initially tempting to think that something $\mathrm{X}$ comes in degrees if there can be much $\mathrm{X}$, little $\mathrm{X}$, more $\mathrm{X}$, or less $\mathrm{X}$. However, reflection on substances shows otherwise. There

\footnotetext{
${ }^{13}$ A proponent of representationalism, a view defended by Millikan (1984), Fodor (1987), and Dretske (1988), might hold this. See Schwitzgebel (2015, sect. 1.1) for an introduction to representationalism. Thanks to Ted Poston for helpful discussion.
} 
can be much water, and there can be more lava in the room than there is gold. However, water, lava, and gold clearly do not come in degrees.

In addition to individuals and substances, there are properties. (I take relations to just be a type of property; they might be a dyadic, a triadic, or an $n$-adic property.) Some properties, like being a millionaire or being a citizen, do not come in degrees. Other properties, like mass, distance, and height, come in degrees. ${ }^{14}$ It seems that properties, not substances or individuals, are the most likely candidate to come in degrees. So, we can now narrow our inquiry by asking what sorts of properties come in degrees.

A popular view, what I call the binary view, is that a property does not come in degrees if it's either instantiated or it's not. We say, 'You're either in or you're out' to communicate that a person's membership in our team does not come in degrees. A person is either a citizen or is not; a woman is either pregnant or is not. Citizenship and pregnancy do not come in degrees. The problem with the binary view is that paradigm cases of properties that come in degrees are also either instantiated or not. A lion has strength or it does not; the earth has mass or it does not. Yet, strength and mass are paradigm degreed properties. Hence, the binary view is a non-starter. It follows that one should not infer that beliefs do not come in degrees on the basis of that fact that you either believe or you don't. ${ }^{15}$

Why do we think that strength and mass come in degrees? We recognize that a lion can have more strength than a gazelle; one lion can have more mass than another. In light of the reflections made thus far, I propose the following definition:

\footnotetext{
${ }^{14}$ Bigelow and Pargetter (1988) use 'quantity' to denote the properties that I am saying come in degrees.

${ }^{15}$ I am thankful to Kokyong Lee, Andrew Melnyk, and John Turri for helpful discussion.
} 
Degrees Analysis: $X$ comes in degrees if and only if, possibly, there is some object $O 1$ and some object $O 2$ such that both $O 1$ and $O 2$ instantiate $X$, and $O 1$ has more $X$ than $O 2$ does.

My analysis determines that strength and mass come in degrees; two objects could instantiate mass, and one could have more mass than the other. It excludes both individuals - such as rocks, trees, and dogs - as well as substances - such as water and lava - since they cannot be instantiated. It also excludes properties such as millionaireness, citizenship, and pregnancy, because there cannot be more or less of them. So, my analysis fits our intuitions.

I am not saying that $X$ comes in degrees if and only if it sounds natural, in ordinary English, to say, 'There is more or less of X.' On the one hand, height comes in degrees, but we do not say, 'Fred has more height than Sally.' However, it seems that Fred can have more height than Sally, and we would express this by saying, 'Fred is taller than Sally.' On the other hand, we can properly say, 'Sally has more knowledge than Fred,' but it does not follow that knowledge comes in degrees. In that sentence, we are only saying that Sally knows more propositions than Fred. So, the focus should be on whether it seems that an object can have more or less of something and not just on whether the sentences sound natural to say.

How are we to understand the expression, ' $O 1$ has more $X$ than $O 2$ does'? ${ }^{16}$ To answer this, I will first provide some metaphysics background. Both my snow globe and my marble have mass, and the former has more mass than the latter. Now this is an odd phenomenon. How is it that both fully instantiate a property, but one object has more of that property than another? Here, we should turn to the distinction between determinates

\footnotetext{
${ }^{16}$ I am thankful to Philip Swenson for helpful discussion of this point.
} 
and determinables. ${ }^{17}$ A determinable is a property like being red, and a determinate is a property like being light red. A property is a determinate relative to a determinable, and there will be many determinates for any determinable. The properties being light red, being maroon, and being orangish-red are all determinates relative to the determinable being red. Furthermore, the properties being red, being orange, and being yellow are determinates relative to the determinable having color. One way to think of it is that a determinate is a specific way of instantiating a determinable, where the instantiation of the determinate entails the instantiation of the corresponding determinable. Returning to the above example, the snow globe and marble both instantiate the same determinable, the property having mass, but they instantiate different determinates. The former instantiates the determinate being $25 \mathrm{~g}$, and the latter instantiates the determinate being 5g. Both of these properties entail having mass.

We can see that all degreed properties are determinables with a corresponding set of determinates. For example, corresponding to the property having mass, there is a set of properties which includes the following elements: being $1 g$, being $1.1 g$, being $5 g$, being $25 \mathrm{~g}$, etc. Corresponding to the property temperature (or having a temperature), there is the set which includes the following: being $2^{\circ} C$, being $3^{\circ} C$, etc. Let us say that the determinates for these degreed properties are 'degree-ordered'. Some determinates are not degree-ordered. Corresponding to the property being colored, there is the following set of determinates: being red, being orange, being yellow, etc. These determinates might even be properly said to be ordered (according to the colors of the rainbow), but they are not degree-ordered in the way that the above determinates for mass

\footnotetext{
${ }^{17}$ The distinction goes back to W.E. Johnson (1921), and is helpfully explained by Bigelow and Pargetter (1988) and Armstrong (1997, c. 4).
} 
and heat are. A red object does not have more color than an orange object in the same way that a $25 \mathrm{~g}$-object has more mass than a $5 \mathrm{~g}$-object.

From the above discussion, we can draw the following necessary condition for degrees.

Determinables-Determinates Condition: If $\mathrm{P}$ comes in degrees, then $\mathrm{P}$ is a determinable with a corresponding set of determinates that are degree-ordered.

So far, I have mostly just been categorizing and labeling properties. I do not intend to answer deeper metaphysical questions regarding what makes a set of determinates degree-ordered, or which of determinates or determinables are more fundamental. Answering these questions is not necessary for the purposes of my paper. ${ }^{18}$

\subsection{The Metaphysics of Degrees and the Anti-Threshold Condition ${ }^{19}$}

Having money comes in degrees; it is a determinable with a set of degree-ordered determinates: having $\$ 1, \ldots$, having $\$ 10, \ldots$, having $\$ 1,000,000, \ldots$, having $\$ 1,000,010$, etc. Call that set ' $M$ '. Now consider the property being a millionaire. This is also a determinable with a set of degree-ordered determinates: having \$1,000,000, having $\$ 1,000,010$, etc. This set is a proper subset of M. Although money possession comes in degrees (a person can have more money than another person), being a millionaire does not come in degrees (even if one person has $\$ 1,000,010$ and another has $\$ 1,000,005$, the former is not more millionaire than the latter). ${ }^{20}$

From this example, I suggest the following:

\footnotetext{
18 They are discussed by Bigelow and Pargetter (1988) and Armstrong (1997, c. 4).

${ }^{19} \mathrm{I}$ am thankful for a referee of this journal whose comments pushed me to develop the points in this section.

${ }^{20}$ Thinking about Mark Kaplan's $(1996,91)$ use of being a millionaire as an illustration of the threshold view of the relationship between belief and confidence (explained in the next section) helped me to realize that I could use being a millionaire here, although for a different purpose.
} 
Anti-Threshold Condition: If $\mathrm{P} 1$ is a determinable that comes in degrees with a corresponding set $\mathrm{D} 1$ of determinates that are degree-ordered, $\mathrm{P} 2$ is a determinable with a corresponding set $\mathrm{D} 2$ of determinates, and $\mathrm{D} 2$ is a proper subset of D1, then P2 does not come in degrees.

The Anti-Threshold Condition has some initially surprising implications. I'll argue that those implications are actually intuitive and thereby increase the plausibility of the condition.

Consider the property having fear. Plausibly, fear comes in degrees; one can have more or less fear. Furthermore, fear is a determinable with a set of determinates: having 1 unit of fear, having 2 units of fear, and so on. Call this set ' $F$ '. Now notice that one can have just a little bit of fear, but still not count as being afraid. For that, one must have, say, 10 units of fear or more. So, being afraid will be a determinable with a corresponding set of determinates that is a proper subset of S. It follows by the AntiThreshold Condition that being afraid does not come in degrees. This is surprising.

But is this a counterintuitive implication that should make us doubt the AntiThreshold Condition? I don't think so. Yes, it is intuitive to say sentences like, 'Fred is more afraid than Sally,' but all we're really saying is that Fred and Sally are both afraid, and Fred has more fear than Sally. We do not have to say that being afraid comes in degrees, but only that having fear does. To be afraid is to have 10 units of fear or more. Upon reflection, that property seems no more likely to come in degrees than having $a$ million dollars or more (or being a millionaire) comes in degrees. To further elicit this intuition, consider the property of being very afraid. ${ }^{21}$ This would just be the property of having, say, 15 units of fear or more. But intuitively, one cannot be more very afraid than another; being very afraid does not come in degrees. Similarly, merely being afraid

${ }^{21}$ Thanks to Allyson Lotz for this example. 
also does not come in degrees. So, this implication of the Anti-Threshold Condition is plausible.

Here is another example. Height comes in degrees and has a corresponding set of degree-ordered determinates: being 1 inch, being 2 inches, and so on. Call that set ' $\mathrm{H}$ '. Now suppose I am in a context in which I am talking about 11-year-old boys, and I say that 'Fred is tall.' The predicate 'is tall', in this context, will pick out something in the neighborhood of the property being 60 inches or more. This property will be a determinable with a set of determinates that is a proper subset of $\mathrm{H}$. Now, the AntiThreshold Condition has the implication that the property picked out by 'is tall' in this context is not something that comes in degrees. This is surprising.

But again, is it counterintuitive that the property picked out by 'is tall' does not come in degrees? I do not think so. It is true that, in that context, we could correctly say, "Billy is taller than Sandy," but such comparative predicates are not attributing the property being tall, since neither Sandy nor Billy need even be tall for that sentence to be true! Such a sentence is only saying that Billy has more height than Sandy, regardless of whether either of them is tall. Hence, we do not have to say that the property picked out by 'is tall', in this context, comes in degrees, but only that height does. Furthermore, the property picked out by 'is tall' is just the property of being 60 inches or more. It seems no more likely to come in degrees than being a millionaire does. To further elicit this intuition, consider that the property picked out by 'is very tall', in that context, is something in the neighborhood of being 65 inches or more. But intuitively, one cannot be more very tall than another; being very tall (or being 65 inches or more) does not come in degrees. So, this implication of the Anti-Threshold Condition is also plausible. 
With the examples above in mind, we can take a bird's eye view of how the AntiThreshold Condition deems certain properties to not come in degrees. ${ }^{22}$ There are what I call degreed properties, which are the properties that come in degrees, and what I call threshold properties, which are the properties of having a degreed property to some degree or more. There is height, which is a degreed property, and there are properties like being tall or being very tall, which are threshold properties. There is fear, which is a degreed property, and there are threshold properties like being afraid or being very afraid. Or, to use a new example, consider the property of having some justification. Justification comes in degrees, but there is also the threshold property of being justified, which is the property of having a certain amount of justification or more. The AntiThreshold Condition plausibly determines that these threshold properties do not come in degrees. We are only tempted to think that threshold properties are also degreed properties because the words we use to refer to the threshold properties are often similar to the words we use to refer to the degreed properties. But on closer consideration, the threshold properties do not actually come in degrees.

\subsection{The Determinables Argument that Beliefs Do Not Come in Degrees}

I am now in a position to present the determinables argument that beliefs do not come in degrees. It is a reductio argument. Suppose that beliefs do come in degrees. Then, by the Determinables-Determinates Condition, belief is a determinable with a corresponding set of degree-ordered determinates. But, I argue, there is no such set that could play that role.

\footnotetext{
${ }^{22}$ Thanks to James Grady for helpful conversation here.
} 
Of course, I cannot examine every proposed set, so I will just examine what I think are the two most plausible candidates. First, perhaps the belief that $p$ has, as its determinates, properties like having a small degree of confidence that $p$, having a moderate degree of confidence $p$, and so on. Unfortunately, these properties cannot be determinates of belief because at least some of them do not entail having the belief that $p$. Someone could have a small degree of confidence that $p$ without also believing that $p$. So, this suggestion fails.

Here is a second suggestion. Suppose that Richard Foley's (1992) threshold view of the relationship between belief and confidence is true. It states that to believe that $p$ is to have a degree a confidence that $p$ higher than a certain threshold. ${ }^{23}$ Then the determinates of belief might be degrees of confidence like having a high confidence, having a very high confidence, having an extremely high confidence, and having a maximal degree of confidence. Furthermore, these determinates would plausibly entail the presence of belief. Hence, this suggestion does not have the weakness of the first suggestion. $^{24}$

The problem with this second suggestion is that it conflicts with the AntiThreshold Condition. Confidence clearly is a determinable that comes in degrees, with properties like having small confidence, having moderate confidence, and so on, as its set of degree-ordered determinates. If the threshold view is true, then the determinates of

\footnotetext{
${ }^{23}$ More specifically, the view is, "To say that we believe a proposition is just to say that we are sufficiently confident of its truth for our attitude to be one of belief" (111).

${ }^{24}$ Of course, not everyone believes in the threshold view, and there are some arguments that belief and confidence are not as closely related as the threshold view states (e.g., see Kaplan (1996), Buchak (2014), Ross and Schroeder (2014), and Weisberg (forthcoming)). But if that is correct, then it is even less plausible that varying degrees of confidence could serve as the determinates of belief.
} 
belief would be a proper subset of that set. But then it follows from the Anti-Threshold Condition that belief does not come in degrees. ${ }^{25}$

In conclusion, belief fails to meet the Determinables-Determinates Condition. On the first suggestion, the proposed set of determinates failed to count as determinates because they did not entail the determinable. On the second suggestion, belief did not satisfy the Anti-Threshold Condition. There appear to be no other plausible candidates for being the set of degree-ordered determinates for belief. The determinables argument concludes that beliefs do not come in degrees. ${ }^{26}$

\section{Conclusion}

In $\S 1-\S 3$, I presented and criticized three arguments that beliefs do not come in degrees. In $\S 2-\S 4$, I presented three arguments that beliefs do not come in degrees, all of which I endorse. I conclude that the preponderance of evidence supports thinking that beliefs do not come in degrees. ${ }^{27}$

\footnotetext{
${ }^{25}$ Thanks to Dan Korman and a referee of this journal for objections to earlier versions of the determinables argument that led to both the formulation of the Anti-Threshold Condition and its application here.

${ }^{26}$ Since the writing of this paper, I learned of van Woudenberg and Peels (forthcoming), which also explores the metaphysics of degrees and the question of whether beliefs come in degrees. I recommend this clearly written and interesting paper for further exploration of this topic.

${ }^{27}$ I appreciate Devin Frank, Isaac Wagner, Leo Yan and especially Philip Swenson for helpful conversation. I also appreciate Nathan Ballantyne, David Christensen, Richard Fumerton, Christopher Gadsden, Joshua Gert, Liz Jackson, Dan Korman, Kok Yong Lee, Kevin McCain, Andrew Melnyk, Blake Roeber, Cory \& Rachel Shain, Paul Weirich, and Julie Zykan for helpful written comments. I am especially thankful to Kenny Boyce, Peter Markie and Matthew McGrath for help on multiple drafts of the paper. I am thankful to my audience at the 2010 meeting of the Central States Philosophical Association and my commentator on that occasion, John Turri, who also helped with multiple drafts of the paper. I am thankful to the audience at the $6^{\text {th }}$ Biennial Rochester Graduate Epistemology Conference and my commentator on that occasion, Brian Barnett, who provided insightful and incisive comments. I am thankful to the students of my Fall 2010 'Theories of Rational Belief' course for helpful discussion and questions. I am thankful to two referees of this journal for insightful and careful comments that led to numerous improvements in the paper. Lastly, I am thankful to the MU Chancellor's Dissertation Fellowship (2009-2010), the Mizzou Advantage Postdoctoral Fellowship (2010-2011), and the Notre Dame Center for Philosophy of Religion (2016-2017) for support while working on this paper.
} 


\section{Works Cited}

Armstrong, David 1997: A world of states of affairs. Cambridge: Cambridge University Press.

Audi, Robert 2011: Rationality and Religious Commitment. Oxford: Oxford University Press.

Bigelow, John and Robert Pargetter 1988: 'Quantities'. Philosophical Studies, 54, pp. 287-304.

Buchak, Lara 2014: 'Belief, Credence and Norms'. Philosophical Studies, 169, pp. 285311.

Christensen, David 2004: Putting Logic in its Place. Oxford: Oxford University Press.

Clarke, Roger 2013: 'Belief is Credence One (in Context)'. Philosopher's Imprint, 13, pp. $1-18$.

Dretske, Fred 1988: Explaining Behavior, Cambridge, MA: MIT Press.

Erikkson, Lina and Alan Hajek 2007: 'What Are Degrees of Belief?' Studia Logica, 86, pp. 183-213.

Fantl, Jeremy and Matthew McGrath 2009: Knowledge in an Uncertain World. Oxford: Oxford University Press.

Fodor, Jerry 1987: Psychosemantics: The Problem of Meaning in the Philosophy of Mind. Cambridge, MA: MIT Press.

Foley, Richard 1992: 'The Epistemology of Belief and the Epistemology of Degrees of Belief'. American Philosophical Quarterly, 29, pp. 111-24. 
Frankish, Keith 2009: 'Partial Belief and Flat-Out Belief'. In Degrees of Belief: An Anthology. Huber, Franz and Christoph Schmidt-Petri (ed) Oxford: Oxford University Press pp. 75-93.

Gardenfors, Peter and David Makinson 1988: "Revisions of Knowledge Systems Using Epistemic Entrenchment" in Theoretical Aspects of Reasoning About Knowledge, edited by Moshe Verde (Morgan Kaufmann). pp. 83-95.

Hacker, P.M.S. 2004: 'On the Ontology of Belief’. In Semantik Und Ontologie. Siebel, Mark and Mark Textor (ed) Frankfurt Ontos Verlag. pp. 185-222.

Harman, Gilbert 1986: Change in View. Cambridge, MA: MIT Press.

Holton, Richard 2008: 'Partial Belief, Partial Intention'. Mind, 117, pp. 27-58.

Huber, Franz 2009: 'Introduction'. In Degrees of Belief: An Anthology. Huber, Franz and Christoph Schmidt-Petri (ed) Dordrecht, Springer, pp. 1-33.

Huber, Franz 2016: 'Formal Representations of Belief'. In Stanford Encyclopedia of Philosophy, https://plato.stanford.edu/entries/formal-belief/, January 11, 2016 version.

Hunter, Daniel 1996: 'On the Relation between Categorical and Probabilistic Belief'. Noûs, 30, pp. 75-98.

Jeffrey, Richard 1970: 'Dracula meets Wolfman: Acceptance vs. Partial Belief'. In Induction, Acceptance, and Rational Belief. Swain, Marshall (ed) Dordrecht: D. Reidel Publishing Company pp. 157-85.

Johnson, W.E. 1921: Logic. Cambridge: Cambridge University Press. Kaplan, Mark 1996: Decision Theory as Philosophy. Cambridge: Cambridge University Press. 
Konek, Jason 2016: 'Probabilistic Knowledge and Cognitive Ability'. Philosophical Review, 125, pp. 509-587.

Lennertz, Benjamin 2015: 'Quantificational Credences'. Philosophers' Imprint, 15, pp. $1-24$.

Millikan, Ruth 1984: Language, Thought, and Other Biological Categories. Cambridge, MA: MIT Press.

Moon, Andrew (forthcoming): ‘The Nature of Doubt and a New Puzzle About Belief, Doubt, and Confidence'. Synthese.

Moon, Andrew (draft): Knowledge and the Doxastic Attitudes.

Pettigrew, Richard 2015: ‘Epistemic Utility Arguments for Probabilism’. In Stanford Encyclopedia of Philosophy, http://plato.stanford.edu/entries/epistemic-utility/, December 17, 2015 version.

Ramsey, Frank 1931: Truth and Probability. London: K.Paul, Trench, Trubner.

Ross, Jacob and Mark Schroeder 2014: 'Belief, Credence and Pragmatic Encroachment'. Philosophy and Phenomenological Research, 88, pp. 259-288.

Rott, Hans 2009: 'Degrees All the Way Down: Beliefs, Nonbeliefs, Disbeliefs'. In Degrees of Belief: An Anthology. Huber, Franz and Christoph Schmidt-Petri (ed) Dordrecht, Springer, pp. 301-340.

Schwitzgebel, Eric 2015: 'Belief’. In Stanford Encyclopedia of Philosophy, http://plato.stanford.edu/entries/belief/, March 24, 2015 version.

Smith, Martin 2016: Between Probability and Certainty. Oxford: Oxford University Press. 
Staffel, Julia 2013: 'Can There be Reasoning with Degrees of Belief?'. Synthese, 190, pp. $3535-3551$.

Sturgeon, Scott 2008: 'Reason and the Grain of Belief'. Noûs, 42, pp. 139-65.

Tang, Weng 2016: 'Reliability Theories of Justified Belief'. Mind, 125, pp. 63-94.

van Woudenberg, Rene and Peels, Rik (forthcoming): 'The Metaphysics of Degrees'.

European Journal for Philosophy of Religion.

Wedgwood, Ralph 2008: 'Contextualism about Justified Belief'. Philosophers' Imprint, 8, pp. 1-20.

Weisberg, Jonathan (forthcoming): 'Belief in Psyontology'. Available at http://www.utm.utoronto.ca/ weisber3/articles/Psyontology.pdf

Zimmerman, Dean 1995: 'Theories of Masses and Problems of Constitution'. The Philosophical Review, 104, pp. 53-110. 